\title{
Activated mouse T-cells synthesize MHC class II, process, and present morbillivirus nucleocapsid protein to primed T-cells
}

\author{
Girdhari Lal, M.S. Shaila, Rabindranath Nayak* \\ Department of Microbiology and Cell Biology, Indian Institute of Science, Bangalore 560012, India
}

\begin{abstract}
A pivotal step in the initiation of T-cell immunity is the presentation of antigenic peptides by major histocompatibility complex (MHC) expressed on antigen presenting cells. The expression of MHC class II molecules by mouse T-cells has not been shown unequivocally. In the present work, we demonstrate that activated mouse T-cells synthesize MHC class II molecules de novo and express them on their surface. Further, we have demonstrated that in vitro activated T-cells take up extra-cellular soluble nucleocapsid protein of a morbillivirus. The internalized antigen goes to antigen processing compartment as shown by co-localization of antigen and LAMP-1 using confocal microscopy. We show that activated T-cells express $\mathrm{H} 2 \mathrm{M}$, a chaperone molecule known to have a role in antigen presentation. Further, we demonstrate that activated T-cells process and present internalized extra-cellular antigen to primed T-cells as shown by IL-2 secretion and in vitro proliferation. The presentation of antigen by T-cells may have implications in immuno-regulation, control of infection by lymphotropic viruses and maintenance of immunological memory.
\end{abstract}

Keywords: T-APC; Major histocompatibility complex II; Antigen presentation; CIITA

\section{Introduction}

The most important steps in the initiation of T-cell immune response is the interaction of T-cells with peptide loaded major histocompatibility complex (MHC) ${ }^{1}$ molecules present on the antigen presenting cells. In general, MHC class II molecules bind peptides formed in endocytic organelles. Antigen presenting cells (APCs) synthesize MHC class II molecules which accumulate in late endosomal and lysosomal compartments (collectively termed MIICs) together with other components required for antigen processing [1]. However, an increas-

\footnotetext{
${ }^{*}$ Corresponding author. Fax: +91 8023602697.

E-mail address: nayak@mcbl.iisc.ernet.in (R. Nayak).

${ }^{1}$ Abbreviations used: T-APC, T-cells as antigen presenting cells; LAMP-1, lysosome-associated membrane protein-1; PMA, phorbol 12-myristate 13-acetate; TCR, T-cell receptor; MHC, major histocompatibility complex; CIITA, class II transactivator.
}

ing number of diverse cell types besides professional APCs have been documented to express class II molecules and act as accessory cells for T-cell stimulation. These include hepatic Kupffer cells [2], epidermal Langerhans cells [3], resting and activated B-cells [4], endothelial cells [5], astrocytes [6], eosinophiles [7], and natural killer cells [8].

The MHC class II expression characterizes the antigen presenting capacity of a cell. Human, guinea pig, and rat T-cells have been shown to synthesize and express class II molecules on their surface after activation by mitogens or alloantigens [9-12]. In contrast, the expression of Ia antigens on murine T-cells is still debated. Although expression of Ia antigen by mouse T-cells has been reported [13-16], subsequent work has shown that Ia antigens might have been acquired passively from contaminating Ia bearing non-T-cells $[17,18]$. These MHC class II expressing $\mathrm{T}$-cells are able to present antigen to other $\mathrm{T}$ cells as reported for human T-cells [19]. In case of mouse 
T-cells, most of the studies demonstrating MHC class II expression have been carried out using long term cultured T-cells or specific T-cell clones. Appearance of MHC class II on naïve mouse T-cells due to de novo synthesis after activation has not been reported.

The expression of MHC class II molecules on activated T-cells can bring about various important immunological functions. Direct MHC class II restricted T-cell-T-cell interactions between TCR peptide specific T-cells and MHC class $\mathrm{II}^{+} \mathrm{T}$-cells expressing the appropriate TCR have been demonstrated in rat [20]. Similar interactions have been postulated to drive immune responses after T-cell vaccination [21,22] and to be of importance in T-cell regulation [23]. TCR peptide immunization, which has been used for protection against multiple sclerosis, appears to function through $\mathrm{T}-\mathrm{T}$ interactions [24]. Idiotypic and anti-idiotypic T-cells interaction had been proposed for maintenance of immunological memory [25].

In the present work, we report that activated mouse T-cells de novo synthesize and express MHC class II molecules on their surface. Activated T-cells take up extra-cellular soluble antigen (morbillivirus nucleocapsid protein), which is processed in endosome/lysosome for presentation to primed T-cells leading to proliferation and cytokine secretion.

\section{Materials and methods}

\subsection{Animal}

Balb/c and C57BL/6 mice were bred and maintained in the Central Animal Facility, Indian Institute of Science, Bangalore, India. Six- to eight-weeks old male mice were used in all experiments.

\subsection{Reagents}

The following antibodies-anti-mouse CD3-PE (clone 145-2C11), purified anti-mouse I-A/I-E (clone 2G9), anti-mouse I-A/I-E-PE (M5/114), anti-mouse CD69-biotin (clone H1.2F3), anti-mouse CD11c (clone HL3), anti-mouse-IgM-FITC (clone II/41), purified antiinvariant chain (CD74; clone $1 n-1)$ and isotype control antibodies as well as recombinant mouse IL-2 were from PharMingen, USA. Polyclonal rabbit anti-mouse Ig and anti-rabbit $\operatorname{IgG} \mathrm{Cy} 3$ conjugated antibody were purchased from Sigma, USA. Donkey anti-rat IgG-FITC was obtained from Jackson ImmunoResearch Laboratories, USA. Anti-mouse TCR $\beta$-PE-Cy5 (clone H57-597), purified anti-mouse CD28 (clone 37.51), anti-mouse I-A/ I-E-biotin (clone M5/114), Streptavidin-PE, and Streptavidin-FITC were procured from e-Bioscience (USA). Anti-LAMP-1 (1D4B) antibody was from Santa Cruz Biotechnology, USA. Anti-mouse H2M antibody (clone
2C3a) was a generous gift from Dr. L. Karlsson, Johnson \& Johnson Pharmaceutical Research and Development, USA. LAMP-1 and H2M antibodies were conjugated with FITC and TRITC, respectively, using standard protocol [26].

Recombinant Rinderpest virus (RPV) nucleocapsid protein (N) was expressed in Escherichia coli and purified as described earlier [27]. RPV nucleocapsid protein has been earlier shown to elicit good $\mathrm{CD}^{+}$and $\mathrm{CD} 8^{+} \mathrm{T}$ cell responses in vivo and in vitro in the mouse model as well as in cattle $[27,28]$.

\subsection{Purification of T-cells}

Mice were sacrificed by cervical dislocation and lymph nodes (inguinal, posterior axillary, internal axillary, and popliteal) were removed. Single cell suspensions were panned for $1 \mathrm{~h}$ in FBS coated plate (Falcon). Unbound cells were harvested and complement mediated lysis was performed using anti-mouse Ig, antimouse MHC class II (clone m5/115), anti-mouse CD11c and rabbit complement. Mononuclear cells were purified by density gradient centrifugation on Histopaque-1077 (Sigma, USA). Cells were further panned on anti-mouse Ig antibody coated plate for $1 \mathrm{~h}$ in complete medium (RPMI-1640 supplemented with $25 \mathrm{mM}$ Hepes, $100 \mu \mathrm{g} /$ $\mathrm{ml}$ penicillin, $100 \mu \mathrm{g} / \mathrm{ml}$ streptomycin, $20 \mu \mathrm{g} / \mathrm{ml}$ gentamicin, and 10\% FBS). Unbound cells were harvested and purity of T-cells was checked by FACS.

\subsection{In vitro activation of $T$-cells}

Purified T-cells $\left(4 \times 10^{6}\right)$ were treated with PMA $(500 \mathrm{ng} / \mathrm{ml})$ and ionomycin $(50 \mathrm{ng} / \mathrm{ml})$ for $6 \mathrm{~h}$ in complete medium in a final volume of $1.5 \mathrm{ml}$ in 24 -well plates. Cells were harvested and washed with Hank's balanced salt solution. Purified T-cells were also activated with IL2 , concanavalin-A, anti-TCR $\beta$ antibody or anti-CD28 and plate bound anti-CD3 antibody. Twenty four well plates were coated with $10 \mu \mathrm{g} / \mathrm{ml}$ of either anti-mouse CD3 antibody (145-2C11) or anti-mouse TCR $\beta$ antibody (H57.597) in PBS overnight at $4{ }^{\circ} \mathrm{C}$, and then washed with medium. Purified T-cells $\left(4 \times 10^{6}\right.$ cells/well $)$ were cultured in anti-CD3 coated plate with soluble antiCD28 antibody $(1 \mu \mathrm{g} / \mathrm{ml})$ or into anti-TCR $\beta$ antibody coated plates in complete medium for $8 \mathrm{~h}$ at $37^{\circ} \mathrm{C}$ in $5 \%$ $\mathrm{CO}_{2}$ incubator. Cells were in vitro activated with concanavalin-A $(1 \mu \mathrm{g} / \mathrm{ml})$ or recombinant mouse IL-2 (200 U) in complete medium for $8 \mathrm{~h}$ at $37^{\circ} \mathrm{C}$ in $5 \% \mathrm{CO}_{2}$ incubator. Cells were harvested, washed and stained for MHC class II, and analyzed by FACS.

\subsection{In vivo activation of $T$-cells}

Balb/c mice were injected with purified recombinant nucleocapsid protein of Rinderpest virus ( $50 \mu \mathrm{g} / \mathrm{mouse})$ 
in CFA subcutaneously and sacrificed after 5 days. Single cell suspensions from lymph nodes (inguinal, popliteal, and axillary) and spleen were made. RBCs were removed from spleen using ACK lysis buffer $(0.15 \mathrm{mM}$ $\mathrm{NH}_{4} \mathrm{Cl}, 1 \mathrm{mM} \mathrm{KHCO}_{3}$, and $0.1 \mathrm{mM}$ EDTA). Mononuclear cells were purified by density gradient centrifugation using Histopaque-1077. Cells were surface stained for TCR $\beta$, CD69, I-A/I-E, and isotype control antibodies. Cells were analyzed by FACS.

\subsection{FACS analysis}

Purified T-cells were surface stained with purified anti-mouse I-A/I-E or anti-mouse CD69-biotin conjugate or isotype control antibodies. Briefly, cells were incubated in $10 \%$ FBS containing PBS for $20 \mathrm{~min}$ at $4{ }^{\circ} \mathrm{C}$. Cells were washed with PBS containing $0.2 \%$ BSA and $0.01 \%$ sodium azide, and incubated with antibody conjugates for $30 \mathrm{~min}$ on ice. Purified antibody or biotin conjugated antibody were used as primary antibodies followed by anti-rat-IgG FITC conjugate or streptavidin-FITC, respectively. Flow cytometric analysis was performed on FACSscan (BD Bioscience, USA) and the data was analyzed using WinMDI 2.8 software.

\subsection{Confocal microscopy}

In vitro activated T-cells $\left(5 \times 10^{6}\right.$ cells/well $)$ were cultured for $3 \mathrm{~h}$ in the presence of $\mathrm{N}$ protein $(100 \mu \mathrm{g} / \mathrm{ml})$ in complete medium. Cells were washed and fixed with $3 \%$ paraformaldehyde for $15 \mathrm{~min}$ on ice and permeabilised using permeabilisation solution (e-Bioscience, USA) for $10 \mathrm{~min}$ on ice. Cells were incubated with rat anti-LAMP1-FITC antibody, rat anti-mouse H2M-TRITC antibody, anti-mouse invariant chain antibody, rat anti-I-A/ I-E-biotin antibody or rabbit anti-N antibody for $30 \mathrm{~min}$ on ice in the presence of permeabilisation solution. Cells were incubated with secondary antibodies, streptavidinFITC, streptavidin-TRITC, and anti-rabbit IgG-Cy3 conjugates for $30 \mathrm{~min}$ on ice and were washed twice with permeabilising solution and finally with PBS. Cells were visualized under confocal microscope using $100 \times$ objective (Leica Microsystems, Germany). In these experiments, isotype control antibody stainings were performed and visualized under microscope. Cells stained with isotype control antibodies have not shown significant fluorescence (data not shown).

\subsection{Radiolabelling and immunoprecipitation}

Radiolabelling and immunoprecipitations were performed as described earlier [29]. Purified T-cells were activated with PMA/ionomycin for $6 \mathrm{~h}$. Before radiolabeling, cells were incubated for $1 \mathrm{~h}$ in methionine-deficient RPMI-1640 (Sigma) supplemented with 5\% dialyzed FBS. The cells were then pelleted and re-sus- pended in the same medium at $4 \times 10^{7}$ cells $/ \mathrm{ml}$ and metabolically labeled by $20 \mathrm{~min}$ pulse incubation with $200 \mu \mathrm{Ci} /$ $\mathrm{ml}\left[{ }^{35}\right.$ S]methionine protein labeling mix (Perkin-Elmer, USA). After the pulse, the cells were pelleted, unincorporated radiolabel removed by washing, and the cells were resuspended at $2 \times 10^{6}$ cells $/ \mathrm{ml}$ in ice-cold ( 0 chase) or prewarmed RPMI medium containing 5\% FCS. The cells in the prewarmed media were then incubated for $0.5,1,2$, or $3 \mathrm{~h}$ at $37^{\circ} \mathrm{C}$ in a $5 \% \mathrm{CO}_{2}$ atmosphere.

After the pulse-chase, the cells were pelleted and lysed in $0.5 \%$ Triton $\mathrm{X}-100,300 \mathrm{mM} \mathrm{NaCl}, 50 \mathrm{mM}$ Tris, $\mathrm{pH}$ 7.4, and complete protease inhibitor cocktail (PharMingen, USA). Nuclei and debris were removed by centrifugation. The cell lysates were pre-cleared first, by incubation with rabbit anti-mouse IgG (Sigma, USA) and Protein-A-agarose (Bangalore, Genie, India) overnight at $4{ }^{\circ} \mathrm{C}$. Lysates were incubated with MHC class II antibody (2G9 clone; PharMingen, USA) for $2 \mathrm{~h}$. Immune complexes were precipitated using Protein-Gagarose (Sigma, USA). Aggregate immune-complexes were washed three times in $0.5 \% \mathrm{NP} 40,30 \mathrm{mM} \mathrm{NaCl}$, $50 \mathrm{mM}$ Tris, $\mathrm{pH}$ 7.4. The beads were then resuspended in Laemmli sample buffer containing 3\% SDS and either incubated for $1 \mathrm{~h}$ at room temperature or boiled for $3 \mathrm{~min}$. The immunoprecipitates were analyzed by electrophoresis using 10\% SDS-PAGE. The gels were treated with salicilate and dried. The gel was subjected to fluorography and exposed to phosphoimager plate for $16 \mathrm{~h}$ and scanned.

To detect synthesis of MHC class II molecule by antigen activated $\mathrm{T}$ cells, naïve mouse splenocytes $\left(2 \times 10^{6}\right.$ cells/well) were pulsed with $\mathrm{N}$ protein $(100 \mu \mathrm{g} / \mathrm{ml})$ in $24-$ well plates in complete medium. Cells were incubated for $12 \mathrm{~h}$ and then fixed with $0.5 \%$ paraformaldehyde and used as antigen presenting cells. In vivo antigen primed T-cells were purified from lymph node cells of mice 5 days after immunization with $\mathrm{N}$ protein $(50 \mu \mathrm{g})$ in Freund's complete adjuvant. These T-cells were cultured in the presence of fixed antigen presenting cells for $6 \mathrm{~h}$ in complete medium and pulse labeled with $\left[{ }^{35} \mathrm{~S}\right]$ methionine $(200 \mu \mathrm{Ci} / \mathrm{ml}$, specific activity $1175 \mathrm{Ci} / \mathrm{mmol})$ for last $2 \mathrm{~h}$ of incubation. Cells were lysed and MHC class II was immuno-precipitated and detected by phosphor-imager as described above.

\subsection{Purification of $\mathrm{CD}^{+}$and $C D 8^{+} T$-cells}

$\mathrm{CD}^{+}{ }^{+} \mathrm{T}$-cells were purified from T-cell populations by complement mediated lysis of $\mathrm{CD}^{+} \mathrm{T}$-cells as described earlier [30]. Briefly, purified T-cells were incubated with anti-CD8 antibody (3.155) or anti-CD4 antibody (GK 1.5) on ice for $30 \mathrm{~min}$. Cells were washed and treated with rabbit complement for $20 \mathrm{~min}$ on ice, dead cells were removed using Histopaque-1077 density gradient centrifugation. Depletion was checked by FACS using anti-mouse CD4 antibody (clone H129.19) and 
anti-mouse CD8 antibody (clone 53-6.7) and purity of $\mathrm{CD}^{+} \mathrm{T}$ and $\mathrm{CD} 8^{+} \mathrm{T}$ cells was $>98 \%$ (data not shown).

\subsection{In vitro proliferation assay}

Purified, in vitro activated T-cells were incubated with purified $\mathrm{N}$ protein $(100 \mu \mathrm{g} / \mathrm{ml})$ in complete medium for $12 \mathrm{~h}$. After incubation, cells were washed with RPMI medium, irradiated (3000 rad) and used as antigen presenting cells (T-APCs) for in vitro proliferation assay. Antigen primed responder T-cells were purified from lymph node cells of $\mathrm{N}$ immunized mouse 5 days after immunization. Purified primed responder cells $\left(4 \times 10^{5}\right.$ cells/well) were incubated with different number of irradiated T-APCs in flat bottom 96-well plates in a final volume of $200 \mu \mathrm{l}$ and incubated for $72 \mathrm{~h}$ in a humidified $\mathrm{CO}_{2}$ incubator. $\left[{ }^{3} \mathrm{H}\right]$ Thymidine $(1 \mu \mathrm{Ci} /$ well $)(85 \mathrm{Ci} / \mathrm{mmol}$, Perkin-Elmer) was added to cells in the last $16 \mathrm{~h}$ of incubation. Cells were harvested on glass fiber filters using semi-automated cell harvester (Nunc) and the incorporated radioactivity was measured in a scintillation spectrophotometer.

\subsection{IL-2 secretion assay}

Stimulator cells were generated as described above and fixed with $0.5 \%$ paraformaldehyde for $5 \mathrm{~min}$ on ice. Cells were washed and cultured with responder T-cell $\left(5 \times 10^{5}\right.$ cells/well $)$ in a final volume of $200 \mu$ in flat bottomed 96-well plate in complete medium. Culture supernatant was harvested after $36 \mathrm{~h}$ of incubation and IL-2 was detected employing IL-2 ELISA kit (e-Bioscience, USA).

\subsection{RT-PCR analysis}

Total RNA was prepared from purified PMA/Ionomycin activated T-cells using TRIzol reagent according to manufacturer's instruction (Life Technology, USA). Primer sequences used for amplification of $\mathrm{H} 2 \mathrm{M} \alpha$ (NM_010386.2), Ii (NM_010545.2), I-A $\alpha$ chain (AY452201.1), I-A $\beta$ chain (AY452202.1), I-E $\alpha$ chain (X54427.1), and I-E $\beta$ chain (X00958.1) were designed using software from Integrated DNA Technology, USA. The GAPDH, total mCIITA, type I, type III and type IV were as published [31]. The sequence of primers are as follows. GAPDH: sense 5'-AACGACCCCTTCATT GAC-3' and anti-sense 5'-TCCACGACATACTCAG CAC-3' (predicted size $=191 \mathrm{bp}$ ). $\mathrm{H} 2 \mathrm{M} \alpha$ : sense $5^{\prime}$-ACC CCAGAACGCCCTGCC-3' and anti-sense 5'-GCTCT

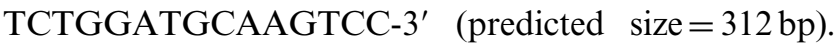
Invariant chain (Ii): sense $5^{\prime}$-AGGACACGGCAAAT GAAGTC- $3^{\prime}$ and anti-sense 5'-CCATGATCCTAC AGGCTGCT $-3^{\prime}$ (predicted size $=319 \mathrm{bp}$ ). I-A $\alpha$ chain: sense $5^{\prime}$-GGACAACATCTTCCCACCTG-3' and antisense 5'-GCAGGCCTTGAATGATGAAG-3' (predicted size $=326 \mathrm{bp}$ ). I-A $\beta$ chain: sense 5'-CAACCACCACA ACACTCTGG- $3^{\prime}$ and anti-sense $5^{\prime}$-CTGACTCCTGTG ACGGATG-3' (predicted size $=346 \mathrm{bp}$ ). I-E $\alpha$ chain: sense 5'-ACACACCATCATCCAGGCAGAGTT-3' and anti-sense 5'-TCTGGAGTGTTGTTGGAACGC TCT-3' (predicted size $=234$ bp). I-E $\beta$ chain: sense $5^{\prime}$-A AGGACAGTCTGGACTTCAGCCAA- $3^{\prime}$ and antisense 5'-AGGGATAAACAGCCATCAGGAGCA-3' (predicted size $=204 \mathrm{bp}$ ). Total mCIITA: sense $5^{\prime}$-AC GCTTTCTGGCTGGATTAGT- $3^{\prime}$ and anti-sense $5^{\prime}-\mathrm{T}$ CAACGCCAGTCTGACGAAGG-3' (predicted size = $342 \mathrm{bp}$ ). Anti-sense primer for type I, III, and IV mCIITA: 5'-GGTCGGCATCACTGTTAAGGA-3'. Sense primer type I mCIITA: 5'-AAGAGCTGCTCTCACGGGAAT$3^{\prime}$ (predicted size $=264 \mathrm{bp}$ ). Sense primer type III mCIITA: 5'-TCTTACCTGCCGG AGTT-3' (predicted size $=100 \mathrm{bp}$ ). Sense primer for type IV mCIITA: $5^{\prime}-\mathrm{GA}$ GACTGCATGCAGGCAGCA-3' (predicted size = $129 \mathrm{bp})$. Reverse transcription of RNA ( $1 \mu \mathrm{g})$ into cDNA was performed in the presence of Oligo(dT) ${ }_{18 n}$ primer and RevertAid M-MuLV Reverse Transcriptase (MBI Fermentas) as per manufacturer's instructions. Reverse transcribed cDNA was amplified in the presence of specific sense and anti-sense primer and DNA Taq polymerase (MBI Fermentas). Thirty cycles of PCR $\left(93^{\circ} \mathrm{C}\right.$ for $30 \mathrm{~s}, 57^{\circ} \mathrm{C}$ for $20 \mathrm{~s}, 72^{\circ} \mathrm{C}$ for $20 \mathrm{~s}$ ) was followed by $5 \mathrm{~min}$ extension incubation at $72^{\circ} \mathrm{C}$. Negative controls included all reagents and primers without cDNA. GAPDH was amplified as positive control. PCR products were resolved on $2.0 \%$ agarose gels and were confirmed by size comparison with $100 \mathrm{bp}$ ladder.

\section{Results}

\subsection{Expression of MHC class II by activated T-cells}

To test for cell surface expression of MHC class II molecules by activated mouse T-cells, purified T-cells from naïve mice were stimulated in vitro with phorbol 12-myristate 13-acetate (PMA) and ionomycin. The purity of T-cells was detected by FACS after staining with anti-CD3, anti-CD11c and anti-IgM antibody and they are $99 \%$ pure (Fig. 1). The combination of PMA/ ionomycin is routinely used as a TCR-independent model to study T-cell activation and proliferation [32,33]. PMA/ ionomycin treatment has been shown to positively select $\mathrm{CD}^{+} \mathrm{T}$-cells in thymocyte cultures [34] and modulate $\mathrm{T}$ helper and T cytotoxic subsets [35]. Activation of T-cells after treatment with PMA/ionomycin was monitored by FACS after staining with CD69, a very early activation marker. Our result shows that all cells are activated after PMA/ionomycin treatment (Fig. 2A). We have monitored the expression of MHC class II molecules on naïve mouse T-cells after in vitro activation with PMA/ionomycin and the results are shown in Fig. 2B, which dem- 


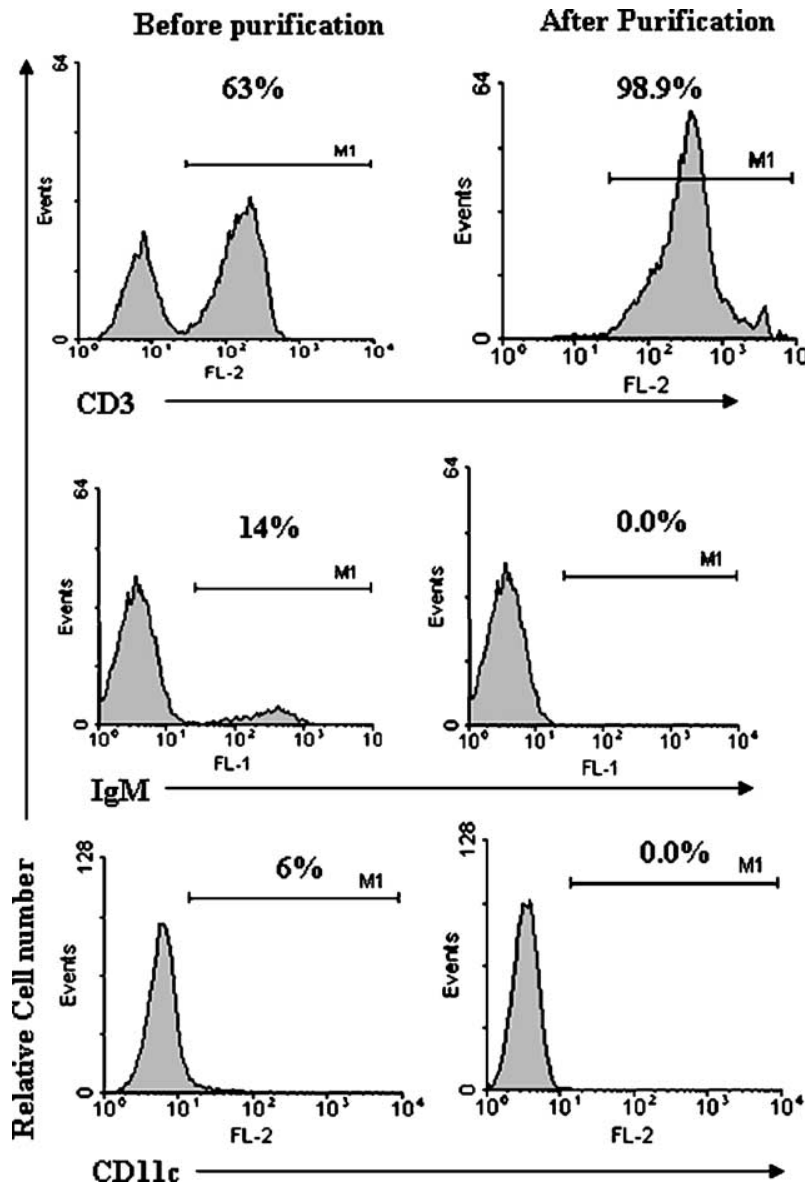

Fig. 1. Purity of T-cells. T-cells were purified from naïve mouse as described in Section 2. Cells were stained with fluorochrome-conjugated antibodies and isotype control antibodies. The purity was detected by FACS. Marker (M1) were set according to isotype control antibody staining.

onstrates the expression of MHC class II molecules. To detect the expression of MHC class II on $\mathrm{CD}^{+}$and $\mathrm{CD}^{+}{ }^{\mathrm{T}}$-cells, purified $\mathrm{CD} 4^{+}$or $\mathrm{CD} 8^{+} \mathrm{T}$-cells were activated in vitro with PMA/ionomycin and stained for MHC class II molecule. The results (Fig. 2C) show that $\mathrm{CD}^{+}{ }^{+} \mathrm{T}$-cells express MHC class II molecules but not CD8 ${ }^{+}$T-cells. We observed that surface expression of MHC class II on purified $\mathrm{CD} 4^{+} \mathrm{CD} 8^{+}$mixed T-cells (Fig. 2B, iii) is almost similar to that expressed on purified $\mathrm{CD}^{+} \mathrm{T}$ cell (Fig. 2C). This MHC class II staining in the mixed population is probably due to acquisition of MHC class II by $\mathrm{CD} 8^{+} \mathrm{T}$ cells from $\mathrm{CD} 4^{+} \mathrm{T}$-cells as it has been reported earlier that activated $\mathrm{CD} 8^{+} \mathrm{T}$-cells acquire surface molecules from other cells [36-38]. When we analyzed the expression of MHC class II on mixed population of purified T-cells, we see the presence of MHC class II on both $\mathrm{CD}^{+}$and $\mathrm{CD}^{+}$T-cells which could be due to acquisition of MHC class II from $\mathrm{CD} 4^{+}$ T-cells by $\mathrm{CD}^{+} \mathrm{T}$ cells (Fig. $2 \mathrm{~B}, \mathrm{v}$ and vi). Further, expression of MHC class II in cells activated by concanavalin-A, plate bound anti-CD3 and soluble anti-CD28, plate bound anti-TCR $\beta$ antibody or purified recombinant IL-2 was tested. The results (Fig. 2D) show that Tcells after activation by the above-mentioned reagents also express MHC class II molecules.

To obtain evidence for the expression of MHC class II by T-cells activated in vivo, mice were immunized with $\mathrm{N}$ protein and after 5 days, the expression of MHC class II was tested. The results given in Fig. 3 show that in vivo activated T-cells express MHC class II molecules on their surface. However, this experiment cannot completely rule out the possibility of passive acquisition of MHC class II molecules from other APCs as reported earlier $[17,18]$.

\subsection{De novo synthesis of MHC class II molecules by activated T-cells}

Mouse T-cells have been shown to acquire MHC II from professional antigen presenting cells $[18,39]$. To test for de novo synthesis of MHC class II, purified T-cells from naïve mouse were activated in vitro and metabolically labeled with $\left[{ }^{35}\right.$ S]methionine and MHC class II synthesis in such labeled T-cells was measured by immuno-precipitation and SDS-PAGE. The results show that upon stimulation in vitro, T-cells synthesize MHC class II molecules endogenously (Fig. 4A). Two protein bands ( $\sim 33 \mathrm{kDa}$ and $\sim 28 \mathrm{kDa})$ seen in Fig. $4 \mathrm{~A}$ and $\mathrm{B}$ correspond to the MHC class II $\alpha$ and $\beta$ chain, respectively. MHC class II expression was further confirmed in antigen driven activated T-cells. The results shown in Fig. 4B demonstrate that antigen driven ( $\mathrm{N}$ protein) activation also leads to expression of MHC class II molecules.

SDS-stable complex formation was monitored by SDS-PAGE under non-reducing condition. MHC class II antibody specific for $\beta$ chain was used, which immunoprecipitates both $\alpha$ and $\beta$ chain along with Ii molecules [29]. Co-immunoprecipitation of $\alpha$ chain by MHC class II antibody indicates that a significant fraction of the newly synthesized class II molecules formed dimers shortly after synthesis. The band for $\alpha$ chain appears denser than the $\beta$ chain band in the immunoprecipitate because newly synthesized Ii chain co-migrates with $\alpha$ chain under the condition used for these experiments (Fig. 4A). After 1-2 h, however, an increasing fraction of $\alpha$ and $\beta$ chain migrated as a band of $52-55 \mathrm{kDa},(\mathrm{C}[\alpha / \beta]$, Fig. 4A). Since these proteins are sensitive to boiling in SDS (Figs. 4A and B), it is indicative of "compact" peptide loaded $\alpha / \beta$ dimers [29,40-42]. Apart from the $C[\alpha / \beta]$, we also see another band $F[\alpha / \beta]$ appearing as early as $0.5 \mathrm{~h}$ which represents the dimers formed by immature $\alpha$ and $\beta$ chain of MHC class II as reported earlier $[29,43]$. Aggregates present in the not-boiled samples dissociated and migrated at $\sim 47 \mathrm{kDa}$ and above. This is probably due to immature stable dimers of $\beta$ chains or disulphide bonded $\beta$ chain with other ER proteins as reported earlier $[29,43]$. We also see the presence of Ii polypeptide by 
A

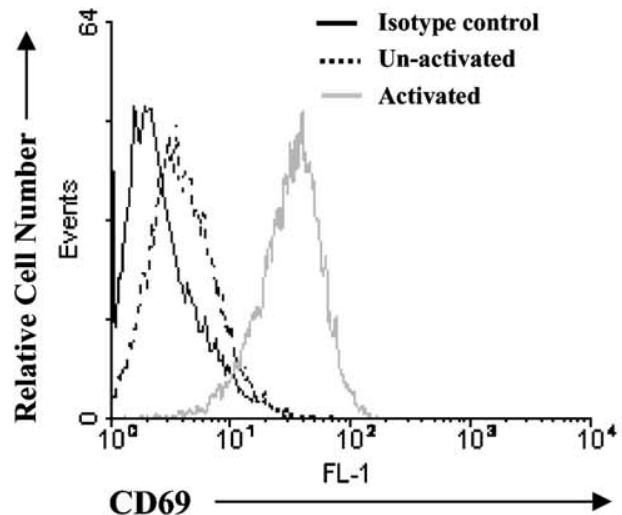

B (i)

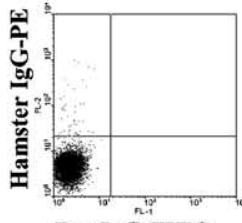

Rat IgG-FITC

(iv)

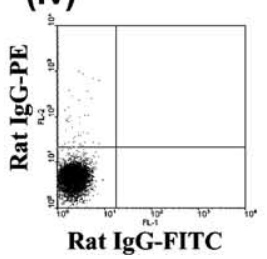

(ii)

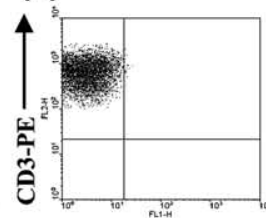

I-A/I-E-FITC

(v)

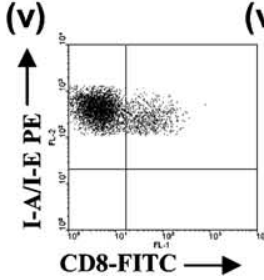

(iii)

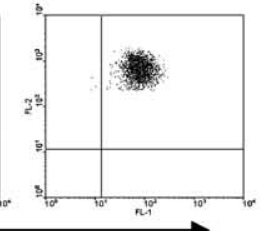

(vi)

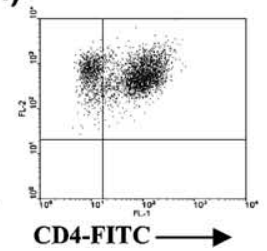

C
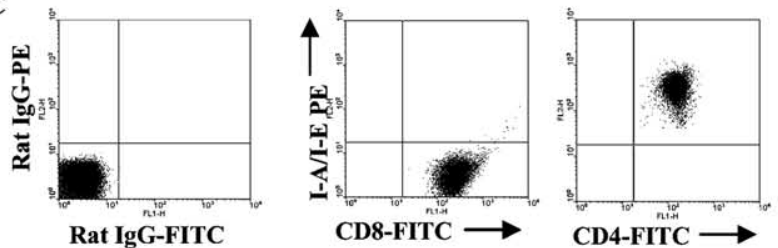

D

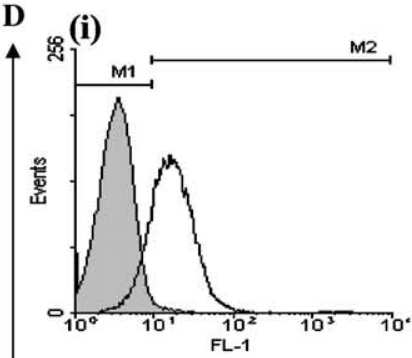

(iii)

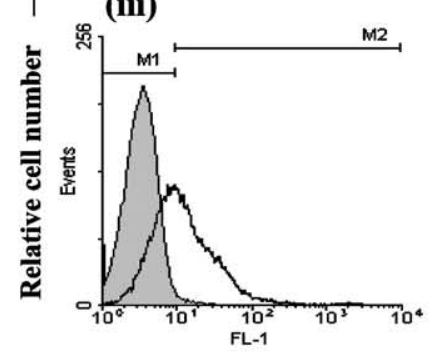

I-A/I-E

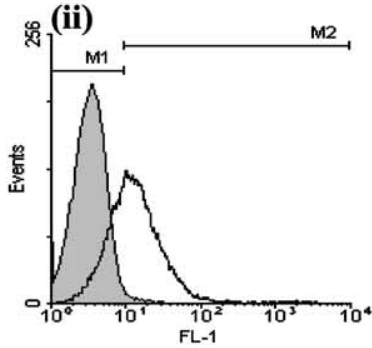

(iv)

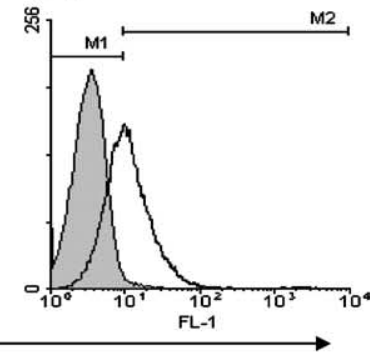

Fig. 2. Expression of MHC II by in vitro activated T-cells. (A) T-cells were purified from naïve mouse lymph nodes and in vitro stimulated with PMA and ionomycin for $6 \mathrm{~h}$. Activation of T cells was detected by surface staining of early activation marker CD69. (B) In vitro activated T-cells showing MHC class II expression. Purified T-cells $\left(4 \times 10^{6}\right)$ were stimulated with PMA and ionomycin for $6 \mathrm{~h}$ and stained for surface marker and analyzed by FACS. Dot plot (i, iv) represents isotype controls, plot (ii) staining of un-activated T-cells, plot (iii, v, vi) staining of activated T-cells. (C) Purified $\mathrm{CD}^{+} \mathrm{T}$-cells or $\mathrm{CD} 8^{+} \mathrm{T}$-cells were activated for $6 \mathrm{~h}$ with PMA/ionomycin and surface stained and analyzed by FACS. (D) Purified mouse T-cells were in vitro activated with (i) combination of plate bound anti-CD3 antibody $(145-2 \mathrm{C} 11 ; 10 \mu \mathrm{g} / \mathrm{ml})+$ purified soluble anti-CD28 antibody $(1 \mu \mathrm{g} / \mathrm{ml})$, (ii) recombinant mouse IL-2 $(200 \mathrm{U} / \mathrm{ml})$, (iii) concanavalin-A $(1 \mu \mathrm{g} / \mathrm{ml})$ or (iv) plate bound anti-mouse TCR $\beta$ antibody $(\mathrm{H} 57.597 ; 10 \mu \mathrm{g} / \mathrm{ml})$. In the presence of these activators, cells were cultured for $8 \mathrm{~h}$ and tested for MHC class II expression by FACS. Filled histogram represents staining with isotype control antibody and open histogram represents staining for MHC class II antibody. Data are representative of three independent experiments.

Western blot in the boiled sample using anti-mouse Ii antibody which confirmed the co-migration of Ii with $\alpha$ chain (data not shown).

To further confirm the finding that MHC class II is endogenously synthesized and transported to the surface of activated mouse T-cells, the cells were treated with brefeldin-A during activation and stained for surface MHC class II. Brefeldin-A is known to block the transport of protein from endoplasmic reticulum to Golgicomplex thereby inhibiting the transport of molecules to the surface of cells $[44,45]$. The data given in Fig. 4C show that MHC class II expression on the surface of activated T-cells is blocked by brefeldin-A treatment.

\subsection{Co-localization of LAMP-1, H2M, MHC class II, and antigen}

In order to investigate whether external antigens taken up by activated T-cells undergo processing through the standard pathway for class II presentation, the expression of LAMP-1, a late endosome-lysosome marker was tested in the activated T-cells. To demonstrate that internalized antigen goes through MHC class II processing pathway, cells were pulsed with $\mathrm{N}$ antigen and co-localization of LAMP-1 and antigen was visualized by confocal microscopy. The results shown in Fig. 5A demonstrate that LAMP-1 is co-localized with $\mathrm{N}$ protein indicating that $\mathrm{N}$ protein has gone into the antigen-processing compartment. To detect the number of T-cells which have taken $\mathrm{N}$ protein, we have performed FACS analysis and results show that $80 \%$ activated T-cells were $\mathrm{N}$ positive (data not shown). To provide further support for the MHC class II processing pathway in activated Tcells, the expression of $\mathrm{H} 2 \mathrm{M}$ and MHC class II molecules together (Fig. 5B) or individually with Lamp-1 (Fig. 5C and $\mathrm{D}$ ) in $\mathrm{T}$ cells were monitored by confocal microscopy. H2M is a chaperone molecule, which plays a crucial role in loading of peptide on major histocompatibility 


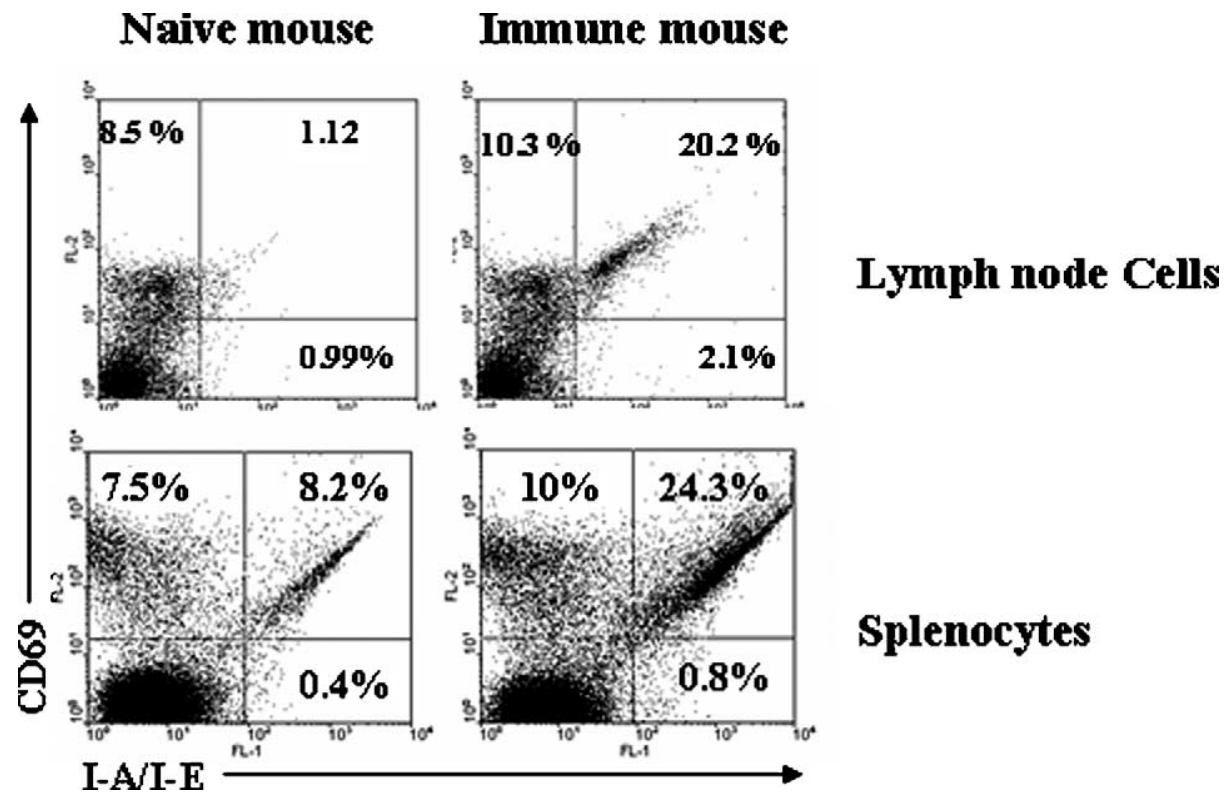

Fig. 3. Expression of MHC class II by in vivo activated T-cells. T-cells were in vivo activated by subcutaneously immunizing mice with $50 \mu \mathrm{g}$ of $\mathrm{N}$ protein in Freund's complete adjuvant. After 5 days, mice were sacrificed, single cell suspension from lymph nodes and spleen were made. Tri-color surface staining of these cells were performed using anti-mouse TCR $\beta$-Cy5PE, anti-mouse CD69-biotin/streptavidin-PE and anti-I-A/I-E antibody/ anti-Rat-FITC. FACS results are gated on TCR $\beta$-positive cells. Quadrants were set according to isotype control antibody staining. Data are representative of three independent experiments.

class II molecules in lysosomal compartments [46]. It is interesting to note that the expression of $\mathrm{H} 2 \mathrm{M}$ and $\mathrm{MHC}$ class II are co-localized in the late endosome/lysosome in activated T-cells. Results given in Figs. 5C and D show that $\mathrm{H} 2 \mathrm{M}$ and MHC class II molecules are present in this compartment where antigen processing takes place. In all the staining, cells were stained with isotype control antibody, which does not give any significant fluorescence (data not shown).

\subsection{Expression of $m R N A$ for Ii, $H 2 M \alpha$ chain, $I-A \alpha$} chain, I-A $\beta$ chain, I-E $\alpha$ chain, I-E $\beta$ chain and CIITA by activated T-cells

To detect the generation of mRNA for Ii, H2M $\alpha$, I-A $\alpha$ chain, I-A $\beta$ chain, I-E $\alpha$ chain, I-E $\beta$ chain and CIITA in activated T-cells, RT-PCR of RNA from activated Tcells was carried out. As shown in Fig. 6A, mRNA for these molecules are present in activated T-cells but not in naïve T-cells of Balb/c mice. Since C57Bl/6 inherently lack MHC class II IE because of a naturally occurring defect in the Ea, gene making them class II $\mathrm{IA}^{+} \mathrm{IE}^{-}$[47]. We have used T-cells from C57BL/6 strain of mice as genetic control for the RT-PCR analysis and shown that activated C57BL/6 T-cells express I-A molecules but not the I-E molecules (Fig. 6B).

The expression of Ii, $\mathrm{H} 2 \mathrm{M} \alpha$, and MHC class II molecules is controlled by class II transactivator protein (CIITA). The CIITA has been referred to as the "master control factor" for these molecules $[31,48,49]$. Therefore, we have examined the expression of CIITA in activated mouse T cells. CIITA expression is regulated by three promoters (pI, pIII, and pIV), producing type I, type III and type IV CIITA [31]. Recently it has become clear that the restriction of these promoters to different cell types or with various stimuli is not so simple [31,48]. We observed that activation dependent expression of CIITA in mouse Tcells involves promoter I and IV but to lesser extent promoter III in PMA/ionomycin activated T-cells (Fig. 6C). It is interesting to note that we also observed a very faint band in un-activated T-cells (total CIITA and type IV CIITA). This low level expression of CIITA is probably not sufficient to drive the expression of MHC class II and other molecules as reported earlier [50,51]. In normal activated splenocytes (un-fractionated $\mathrm{T}$ cells) the expression of all three type CIITA is seen (data not shown).

\subsection{Activated T-cells process and present extra-cellular antigen to other T-cells}

To examine whether mouse T-cells can also present external antigen to other T-cells, purified activated $\mathrm{T}$ cells, were pulsed with Rinderpest virus nucleocapsid protein, and irradiated after $12 \mathrm{~h}$ of culture. These cells were used as antigen presenting cells (T-APCs) in an in vitro proliferation assay. The results shown in Fig. 7A demonstrate that T-APC is able to present antigen to primed, specific T-cells. When activated T-APCs were pulsed with antigen in the presence of chloroquine, they do not stimulate primed T-cells showing that antigen processing has been inhibited in these cells. To test if proliferation signal is coming through MHC class II, 
$\mathbf{A}$

(I)

(II)

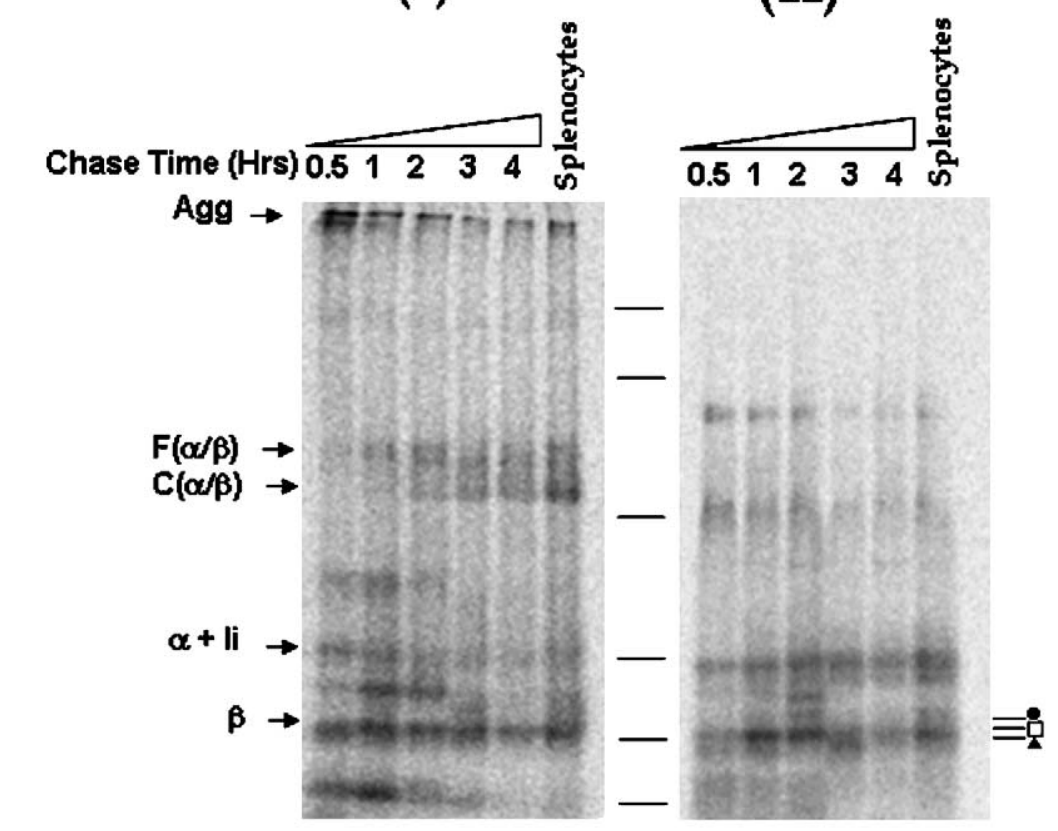

B

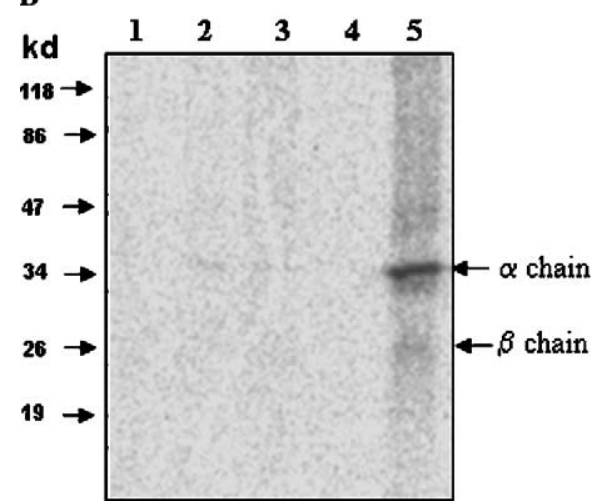

$\mathrm{c}$

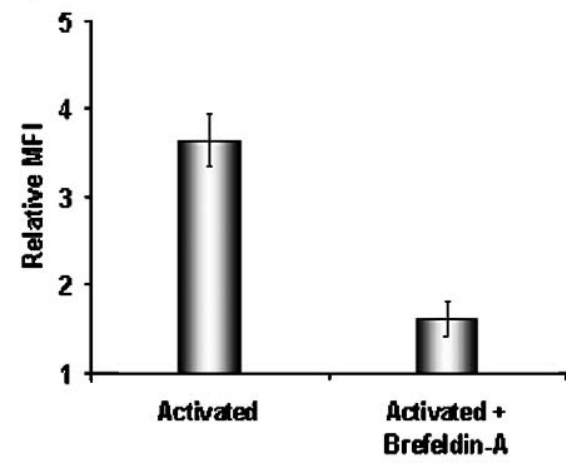

Fig. 4. De novo synthesis of MHC class II by activated T-cells. (A) Purified T-cells $\left(5 \times 10^{6}\right)$ from naïve mice were activated with PMA and ionomycin for $6 \mathrm{~h}$. Cells were pulsed with $\left[{ }^{35} \mathrm{~S}\right]$ methionine for $20 \mathrm{~min}$ and chased for different time points. Immune-complexed bead were divided into two fractions. One fraction was incubated for $1 \mathrm{~h}$ at room temperature in Laemli sample buffer (I) and other fraction was boiled for 3 min (II). Samples were analyzed by $10 \%$ SDS-PAGE followed by phosphor-image analysis. Splenocytes were activated with PMA/ionomycin for $1 \mathrm{~h}$ and pulsed with $\left[{ }^{35} \mathrm{~S}\right]$ methionine as described above and chased for $3 \mathrm{~h}$ and used as positive control for these experiments. Different glycosylation intermediates are also shown. (๑) Core glycosylated; $(\square)$ trimmed intermediate; $(\bullet)$ terminally glycosylated. Molecular weight markers are indicated by the six horizontal lines shown between boiled and not boiled gels. As shown, the markers indicate the migration of the 118, 86, 47, 34, 26, and 19 kDa, respectively. (B) Splenocytes from naïve mouse were pulsed with $\mathrm{N}$ protein $(100 \mu \mathrm{g} / \mathrm{ml})$ and cultured for $12 \mathrm{~h}$ in complete medium. As a control, splenocytes pulsed with antigen were treated with chloroquine $(40 \mathrm{mM})$ during culture. Fixed splenocytes $\left(4 \times 10^{6}\right.$ cells/well $)$ were co-cultured with purified antigen specific T-cells $\left(2 \times 10^{6}\right.$ cells/well $)$ in complete medium in 24 -well plates. Cells were cultured for $6 \mathrm{~h}$ and in the last $2 \mathrm{~h}$, pulsed with $\left[{ }^{35} \mathrm{~S}\right] \mathrm{methio-}$ nine. Lysate from these cells were immuno-precipitated with anti-MHC class II antibody and analyzed on 12\% SDS-PAGE followed by fluorography and phosphorimaging. Lane 1, immunoprecipitation with isotype control antibody; lane 2, with anti-MHC class II antibody from fixed splenocytes only; lane 3, responder immune cells only; lane 4, N protein pulsed splenocytes in the presence of chloroquine along with responder immune T cells; lane 5, fixed splenocytes with responder T-cells. Data are representative of three independent experiments. (C) Purified T cells were in vitro activated with PMA and ionomycin in the presence or absence of brefeldin-A $(10 \mu \mathrm{g} / \mathrm{ml})$. After $6 \mathrm{~h}$ of incubation, cells were harvested and stained for surface MHC class II. Cells were analyzed by FACS and relative MFI (mean fluorescence intensity) were calculated by dividing the MFI of activated cells value with MFI of un-activated cells.

antigen pulsed T-APCs were co-cultured with primed Tcells in the presence of purified anti-mouse MHC class II antibody. In vitro stimulation of primed T-cells with antigen pulsed T-APC leads to secretion of IL-2 as shown in Fig. 7B. Un-stimulated antigen pulsed T-APC and stimulated antigen pulsed T-APC treated with antiMHC class II antibody are not able to induce IL-2 secretion by antigen specific $\mathrm{T}$ cells. These results show that activated mouse T-cells process and present antigen to other T-cells in a MHC class II dependent manner. 

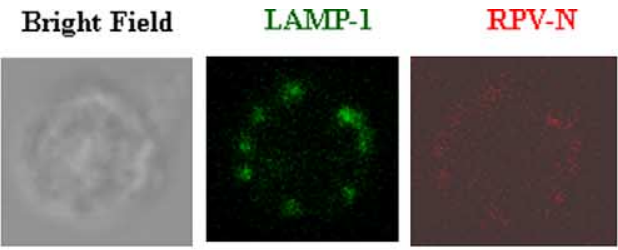

Overlay
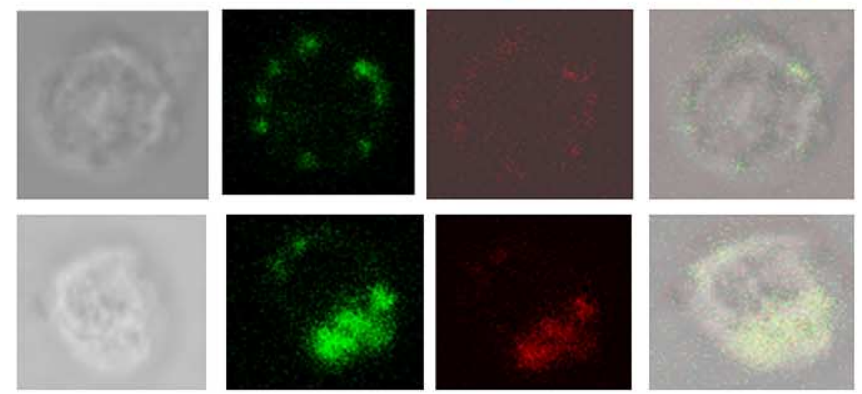

Un-activated

B
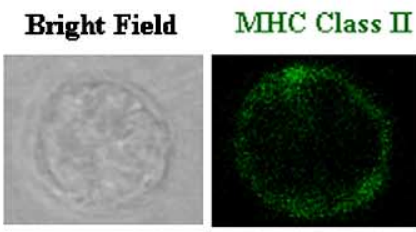

H2M

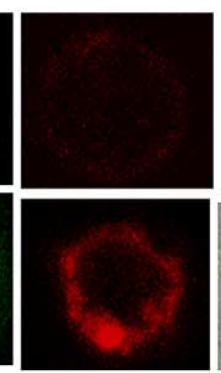

Overlay
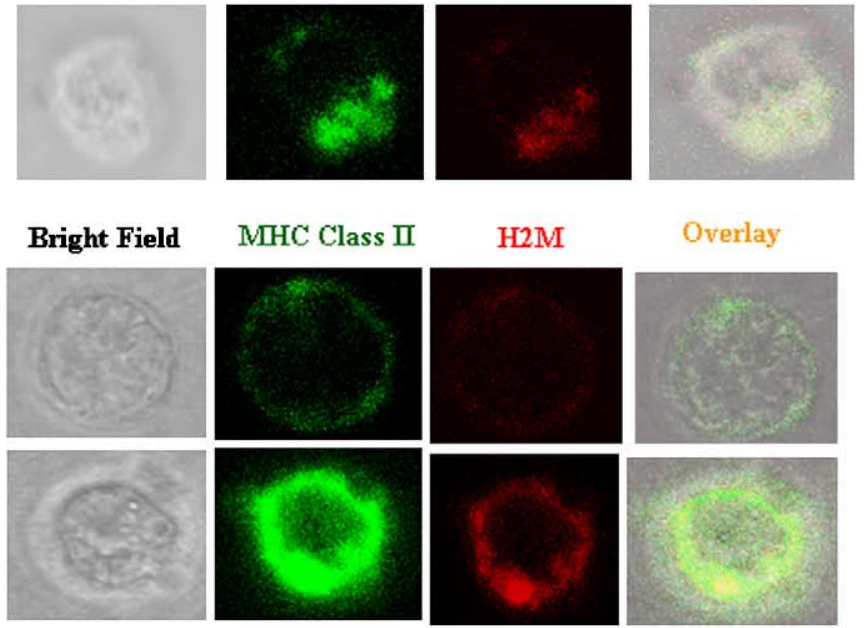

Activated

C Bright Field

Lamp-1
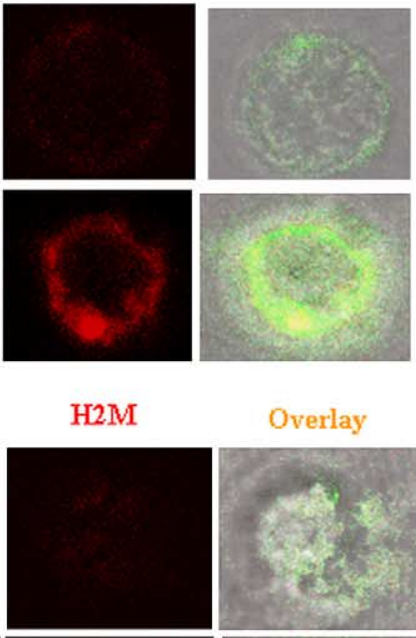

Un-activated
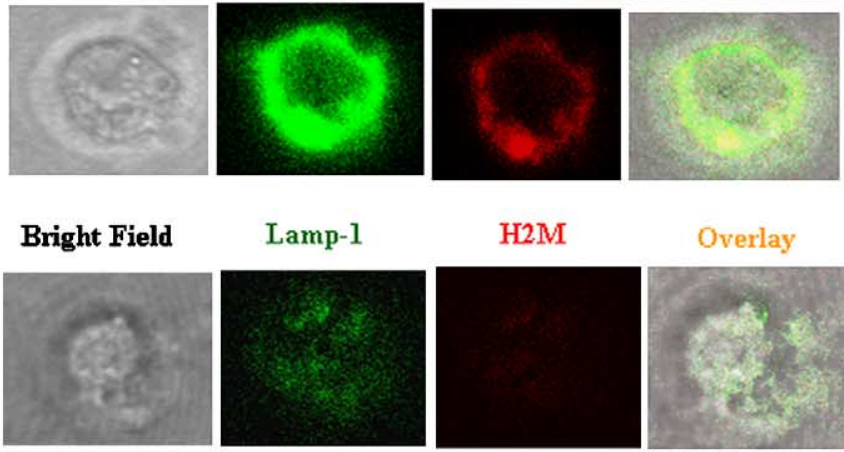

Activated
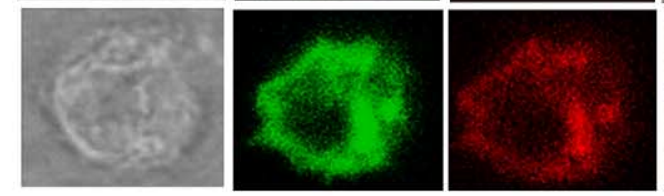

Overlay

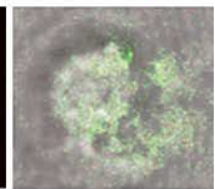

Un-activated

D Bright Field

$$
\text { Lamp-1 }
$$
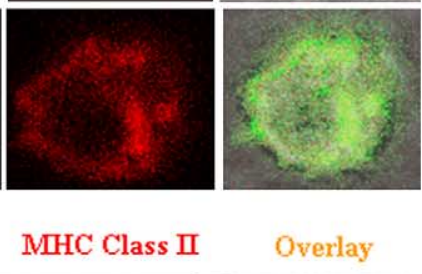

\section{Activated}
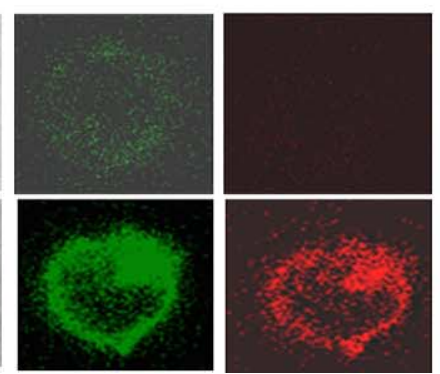

Overlay

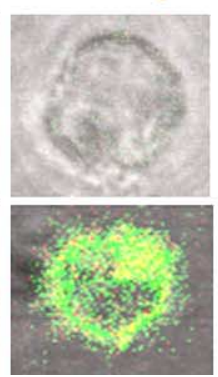

\section{Un-activated}

Activated

Fig. 5. Co-localization of H2M, MHC class II, LAMP-1, and antigen. Purified mouse T-cells were in vitro activated with PMA/ionomycin for 6 h. Intra-cellular staining was performed. Cells were visualized under Confocal microscopy $(100 \times$ objective). Double staining is indicated by a yellow colour in the overlay image. (A) Activated T-cells were cultured with N protein $(100 \mu \mathrm{g} / \mathrm{ml})$ for $3 \mathrm{~h}$. Intracellular staining of cells with anti-mouse LAMP-1-FITC and rabbit anti-N antibody/anti-rabbit IgG-Cy3 was performed. (B) Cells were stained with anti-mouse H2M-TRITC and antimouse MHC II-biotin/streptavidin-FITC. (C) Anti-mouse LAMP-1-FITC and anti-mouse H2M-TRITC. (D) Anti-mouse LAMP-1-FITC and antimouse MHC class II-biotin/streptavidin-TRITC.

\section{Discussion}

In the present work, we have examined the expression of MHC class II molecules and explored the antigen presenting capacity of activated mouse T-cells. The expression of MHC class II molecules in mouse T-cells has been reported using $\mathrm{T}$-cell clones or T-cell lymphoma but not in naïve T-cells [13-16,52,53]. In most of these studies, T-cells were cultured in the presence of mitogens or IL-2. In the present work, we show that culturing of T-cells in the presence of various mitogens leads to expression of MHC class II molecules. Earlier reports on 
A
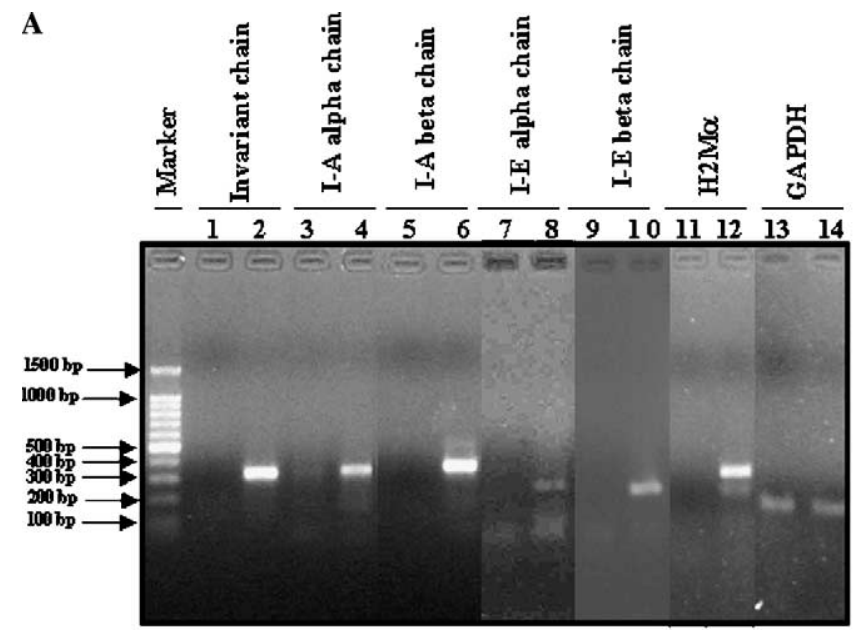

B
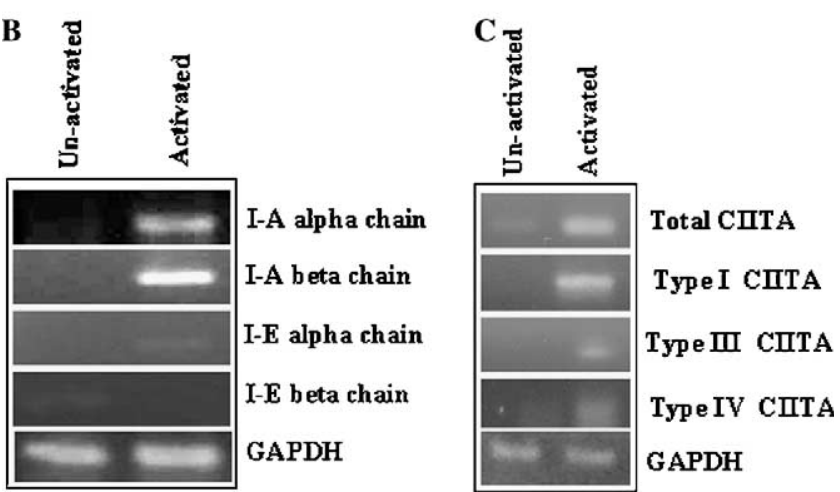

Fig. 6. Activated T-cells synthesize mRNA encoding Ii, I-Ad $\alpha$ chain, I-Ad $\beta$ chain, $\mathrm{H} 2 \mathrm{M} \alpha$, and CIITA. Purified T-cells were activated with PMA/ionomycin for $3 \mathrm{~h}$. cDNA were synthesized using oligo(dT) $)_{18 n}$ primer and expression of transcripts were detected by RT-PCR using gene specific sense and anti-sense primers. GAPDH was used as an internal control. Products were electrophoresed through $2 \%$ agarose gel. (A) Lanes 1, 3, 5, 7, 9, 11, and 13 represent the profile of transcript from the naïve T-cells. Lanes 2, 4, 6, 8, 10, 12, and 14 represent profile of activated T-cells. (B) T-cells from C57BL/6 mice were purified and activated in vitro. Expression of gene was detected by RT-PCR as described above. (C) Expression of CIITA was tested as described earlier [31].

absence of MHC class II expression in long-term cultured specific T-cell clone or -cell lines, needs to be reexamined in the context of expression or defect in the expression of CIITA, which is a master controlling factor. There are reports that activated T-cell acquires MHC class II molecules from other antigen presenting cells $[17,18,39]$. We also observe the presence of MHC class II molecules on ex vivo activated T-cells by FACS. However, FACS analysis does not differentiate between de novo synthesized and passively acquired MHC class II molecules.

In our experimental system, since the cells were activated in vitro in the absence of professional antigen presenting cells, increased expression of MHC class II on the surface is possible via intracellular synthesis, and not by acquisition of MHC class II molecules from other
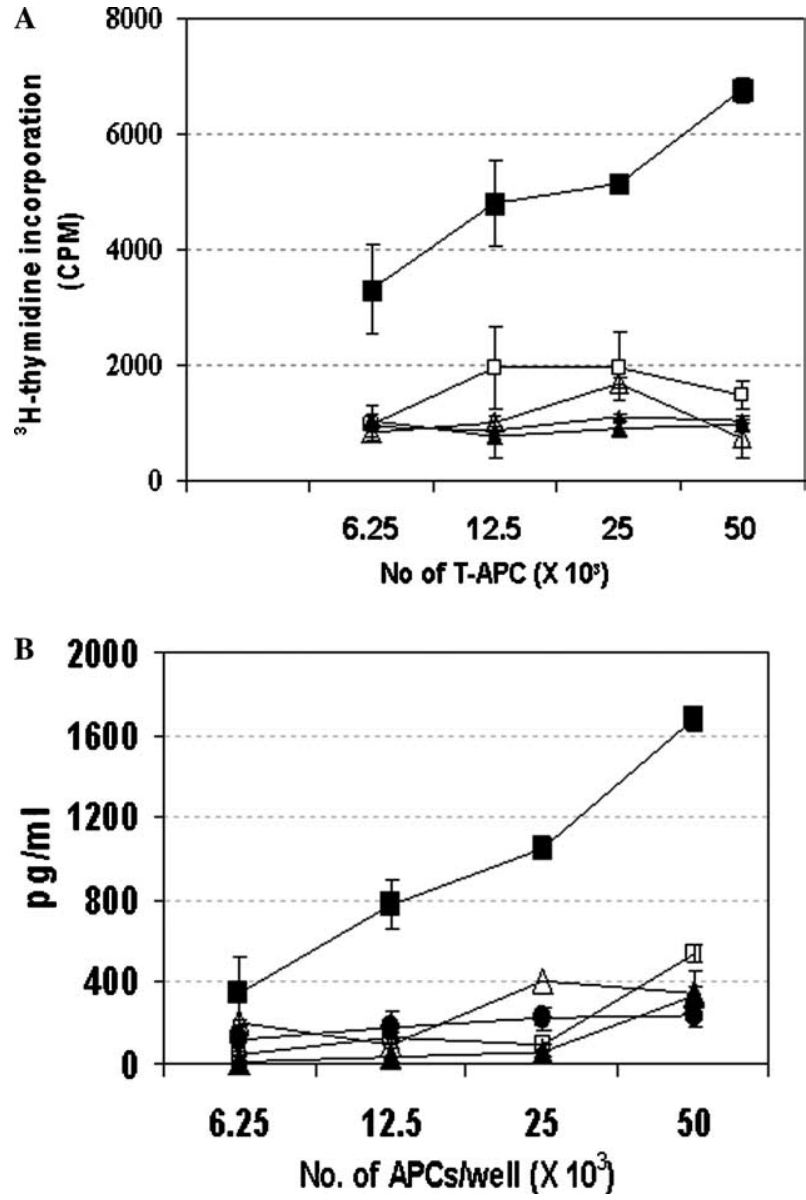

Fig. 7. Processing and presentation of soluble antigen by activated $T$ cells to primed T-cells. (A) In vitro proliferation assay. Purified T-cells $\left(5 \times 10^{6}\right.$ cells/well) from naïve mouse were in vitro activated with PMA and ionomycin for $6 \mathrm{~h}$, pulsed with purified soluble nucleocapsid protein $(100 \mu \mathrm{g} / \mathrm{ml})$ in 24 -well plates. After $12 \mathrm{~h}$ of incubation, T-APC were washed and irradiated. Responder T-cells $\left(4 \times 10^{5}\right.$ cells $/$ well $)$ were cocultured with different number of T-APCs for $72 \mathrm{~h}$ in flat bottom 96 well plate. Result shown is the mean \pm SEM of triplicates. (B) IL-2 secretion. T-APC and responder cells were generated as mentioned above. T-APC was fixed with $0.5 \%$ paraformaldehyde for $10 \mathrm{~min}$ on ice. Responder $\mathrm{T}$ cells $\left(5 \times 10^{5}\right.$ cells/well $)$ were incubated with different number of T-APCs in flat bottom 96-well plates for $36 \mathrm{~h}$ in final volume of $200 \mu \mathrm{l}$ of complete medium. Supernatant was collected and IL-2 secretion was detected by ELISA kit (e-Bioscience, USA). Data shown is the mean \pm SEM of triplicates. $(\triangle)$ represents activated T-cells without N protein, ( $\square$ ) activated T-cells pulsed with RPV-N protein, ( $\square$ ) normal T-cells pulsed with RPV-N protein, $(\boldsymbol{\Delta})$ activated T-cells pulsed with $\mathrm{N}$ protein in presence of chloroquine $(40 \mathrm{mM}),(\boldsymbol{)})$ Activated $\mathrm{T}$ cells pulsed with RPV-N protein but co-cultured in the presence of MHC class II antibody (clone M5/115; 1 g/ml).

APCs as has been reported earlier [17,18]. Metabolic labeling of newly synthesized MHC class II with $\left[{ }^{35}\right.$ S]methionine followed by immunoprecipitation confirms de novo synthesis. The results demonstrate that class II molecules are synthesized endogenously after activation with either PMA/ionomycin or with antigen pulsed APCs. Our result also correlates with earlier published report for other species $[11,12,19]$. This is further 
confirmed by inhibition of surface expression of MHC class II by brefeldin-A. Thus, naïve mouse T-cells are capable of synthesizing MHC class II de novo after activation with mitogens or even by antigen driven activation. Although, MHC class II expression in long term cultured cloned $\mathrm{T}$-cells or T-cell lymphoma or thymus derived cells has been shown $[13,14,16]$, the present work demonstrates that activated mouse $\mathrm{T}$-cells can synthesize MHC class II molecules de novo. Using pulse labeling, immunoprecipitation and analysis of immune complexes under denaturing and non-denaturing condition, we show that newly synthesized MHC class II molecules form SDS-stable complexes similar to that reported for other antigen presenting cells [29]. In addition, the synthesis of transcripts for I-A $\alpha$ chain, I-A $\beta$ chain, I-E $\alpha$ chain, I-E $\beta$ chain, Invariant chain, $\mathrm{H} 2 \mathrm{M} \alpha$ in activated mouse T-cells was confirmed by RT-PCR analysis. The expressions of these molecules are controlled by class II transactivator protein (CIITA) [48,54]. It has also been reported that CIITA knockout mice express MHC class II albeit at a five-fold reduced level [55]. We have examined the expression of CIITA by RT-PCR and interestingly, we find that mouse T-cells use predominantly type I and type IV exon of CIITA but very little of type III exon in comparison to rat T-cells where the usage of type III and type IV exon of CIITA has been reported [12]. Though mouse T-cells express class II transactivator (CIITA), a 'master regulator factor', yet it is not sufficient to drive the expression of MHC class II molecules in naïve cells [48]. The functional activation of CIITA involves phosphorylation of CIITA which can be achieved from signaling through mitogenic triggering [56-58]. Recently, it has been shown that over-expression of CIITA in mouse T-cells leads to induction of tolerance and altered Th1/Th2 balance [59].

Professional antigen presenting cells are known to take up, process and present extra-cellular soluble antigens to T-cells. T-cells are known to express CD40, CD40L and B7 co-stimulatory molecules in activated state, which are needed for activation of responder Tcells, enhanced cell cycle progression and survival $[19,33,60]$. Antigen presentation by resting or naïve Tcells is known to induce anergy to responder T cells [61] and apoptosis in other T-cells [62] perhaps because of lack of co-stimulatory molecules on T-APCs. We explored the possibility of intake of soluble antigen by activated mouse $\mathrm{T}$-cells by pulsing with Rinderpest virus nucleocapsid protein in complete medium for $3 \mathrm{~h}$. The results show that activated T-cells take up antigen. Subsequently by confocal microscopy, we have shown that LAMP-1, a late endosomal and lysosomal marker [63], is seen as part of a cluster in vesicles, indicating that vesicles have been formed during the antigen processing pathway. Co-localization of LAMP-1 with antigen in activated T-cells demonstrates that antigen has entered into the endosomal compartment for processing. We show that $\mathrm{H} 2 \mathrm{M}$ is also expressed in activated T-cells, which is an essential molecule for presentation of peptide on MHC class II. These results show that activated mouse T-cells express $\mathrm{H} 2 \mathrm{M}$ molecules required for antigen presentation. We have also examined the expression of Invariant chain (Ii) in activated mouse T-cells by confocal microscopy. The results demonstrate that Ii molecules are present in activated T-cells (data not shown). The invariant chain functions as a chaperone protein for MHC class II molecules during folding, assembly and transport from endoplasmic reticulum to Golgi complex $[29,43]$. It has been reported earlier that Ii chain is not only required for dimerization or at least partial folding of $\alpha$ and $\beta$ chains but also required to allow newly synthesized class II molecules to escape the quality control mechanism in the ER that prevents the transport of misfolded proteins [29]. The presence of lysosomal enzymes associated with antigen processing remains to be demonstrated.

The functional importance of processing and presentation was examined by in vitro proliferation of primed T-cells and IL-2 secretion. The results show that activated T-cells are capable of presenting antigen to primed $\mathrm{T}$-cells as has been reported in case of human and rat $[11,19,64]$. Further inhibition of processing of extracellular antigen was demonstrated using chloroquine, a known inhibitor of lysosomal enzymes by increasing the $\mathrm{pH}$ [65]. Proliferation and IL-2 secretion are shown to be MHC class II dependent since anti-MHC class II antibody inhibits this function. This shows that the antigen was processed by lysosomal proteolytic enzymes and presented on surface, which is able to functionally trigger the antigen specific T-cells.

We have demonstrated that activated murine $\mathrm{CD}^{+} \mathrm{T}$ cells can process and present antigen through MHC class II molecules. Antigen presentations by T-cells have far-reaching biological consequences. Antigen presentation by T-cells may play a key role in controlling infection by lymphotropic viruses [66,67]. Perhaps, lymphotropic viruses on infecting $\mathrm{T}$-cells regenerate a quick response bringing in both $\mathrm{CD} 4^{+}$help and CTL attack on infected T-cells. Therefore, antigen presentation by $\mathrm{T}$-cells provides an ideal mechanism to protect immune machinery involving T-cells, which needs experimental verifications. The presentation of antigen by $\mathrm{T}$ cells leads to T-cell-T-cell interactions which may lead to proliferation and/or regulation of cognate $\mathrm{T}$-cells as found in auto-immune diseases [20]. T-cell-T-cell interaction has also been proposed to be the basis of $\mathrm{T}$ cell vaccination [21].

\section{Acknowledgments}

We thank Dr. D. Nandi, Department of Biochemistry, Indian Institute of Science, Bangalore for the generous 
gift of 145-2C11 hybridoma, 3.155 hybridoma and antiTCR $\beta$, anti-MHC class II antibody (clone m5/115). We thank Dr. Ranga Uday Kumar, Jawaharlal Nehru Center for Advanced and Scientific Research (JNCSAR), Bangalore for providing GK1.5 cell hybridoma. The FACS and confocal microscope facilities are supported by the Department of Biotechnology, Government of India, under programme support grants (Basic Biology of Microbial Pathogens). G.L. is a senior research fellow of Council of Scientific and Industrial Research, India. This work is supported in part by the Indian Council of Medical Research and Department of Science and Technology, Government of India.

\section{References}

[1] C. Watts, Capture and processing of exogenous antigens for presentation on MHC molecules, Annu. Rev. Immunol. 15 (1997) $821-850$.

[2] P.I. Nadler, R.J. Klingenstein, L.K. Richman, G.B. Ahmann, The murine Kuffer cells. II Accessory cell function in in vitro primary antibody responses, mitogen induces proliferation and stimulation of mixed lymphocyte responses, J. Immunol. 125 (1980) 25212525.

[3] G. Stingl, S.I. Katz, L. Clement, I. Green, E.M. Shevach, Immunological functions of Ia-bearing epidermal Langerhans cells, J. Immunol. 121 (1978) 2005-2013.

[4] J.D. Ashwell, A.L. DeFranco, W.E. Paul, R.H. Schwartz, Antigen presentation by resting B cells. Radiosensitivity of the antigen-presentation function and two distinct pathways of $\mathrm{T}$ cell activation, J. Exp. Med. 159 (1984) 881-905.

[5] J. Pober, M.A. Gimborne, R.S. Cotran Jr., C.S. Reiss, S.J. Burakoff, W. Friers, K.A. Ault, Ia expression by vascular endothelial is inducible by activated T cells and by Human $\gamma$-Interferon, J. Exp. Med. 157 (1983) 1339-1353.

[6] W. Fierz, B. Endler, K. Reske, H. Wekerle, A. Fontana, Astrocytes as antigen presenting cells. I. Induction of Ia antigen expression on astrocytes by $\mathrm{T}$ cells via immune interferon and its effect on antigen presentation, J. Immunol. 134 (1985) 3785-3793.

[7] V. Del Pozo, B. De Andres, E. Martin, B. Cardaba, J.C. Fernandez, S.P. Gallardo, P. Tramon, F. Leyva-Cobian, P. Palomino, C. Lahoz, Eosinophil as antigen presenting cells: activation of $\mathrm{T}$ cell clones and hybridoma by eosinophils after antigen processing, Eur. J. Immunol. 22 (1992) 1919-1925.

[8] M.G. Roncarolo, M. Bigler, J.B. Haanen, H. Yssel, R. Bacchetta, J.E. de Vries, H. Spits, Natural killer cell clones can efficiently process and present protein antigen, J. Immunol. 147 (1991) 781787.

[9] D.J. Schendel, J.P. Johnson, R.L. Evans, R. Wank, Clonal expression of differentiation and Ia-like antigens on allorective human $\mathrm{T}$ lymphocytes, Eur. J. Immunol. 14 (1984) 363-368.

[10] C.R. Lyons, R.G. Cook, T.F. Tucker, J.W. Uhr, Biochemical characterization of alloantigens in guinea pig. II. Comparative peptide mapping of Ia antigens from B cells, T cells and macrophages, J. Immunol. 127 (1981) 1885-1888.

[11] C.P. Broeren, M.H. Wauben, M.A. Lucassen, M. Van Meurs, P.J. Van Kooten, C.J. Boog, E. Claassen, W. Van Eden, Activated Rat $\mathrm{T}$ cells synthesize and express functional major histocompatibility class II antigen, Immunology 84 (1995) 193-201.

[12] M.D. Mannie, J.G. Dawkin, M.R. Walker, B.A. Clayson, M.D. Patel, MHC class II biosynthesis by activated rat $\mathrm{CD}^{+} \mathrm{T}$ cells: development of repression in vitro and modulated by APCderived signals, Cell Immunol. 230 (2004) 33-34.
[13] A.B. Reske-Kunz, T. Diamantstein, Evaluation of antigen presentation by a murine Ia $+\mathrm{T}$ cell clone, BK-B-2.6.C6, Immunology 61 (1987) 489-495.

[14] J.A. Frelinger, J.E. Niederhuber, C.S. David, D.C. Schreffler, Evidence for expression of Ia (H2 associated) antigens on thymusderived lymphocytes, J. Exp. Med. 140 (1974) 1273.

[15] B.A. Osborne, S. Rudicoff, Murine thymocytes and splenocytes Ia antigens are indistinguishable by Two dimensional gel electrophoresis, J. Immunol. 131 (1983) 1386.

[16] L. Grof, N. Koch, V. Schimmacher, Expression of Ia antigens in a murine T-lymphoma variants, Mol. Immunol. 22 (1985) 1371.

[17] P.Y. Arnold, M.D. Mannie, Vesicular bearing MHC class II molecules mediate transfer of antigen from antigen presenting cells to $\mathrm{CD}^{+}$T cells, Eur. J. Immunol. 29 (1999) 1363-1373.

[18] D.M. Patel, P.Y. Arnold, G.A. White, J.P. Nardella, M.D. Mannie, Class II MHC/peptide complex are released from APC and acquired by $\mathrm{T}$ cell responders during specific antigen recognition, J. Immunol. 163 (1999) 5201-5210.

[19] V. Barnaba, C. Watts, M. de Boer, P. Lane, A. Lanzavecchia, Professional presentation of antigen by activated human T cells, Eur. J. Immunol. 24 (1994) 71.

[20] C.P.M. Broeren, M.A. Lucassen, M.J. van Stipdonk, R. van der Zee, C.J. Boog, J.G. Kusters, W. van Eden, CDR1 T-cell receptor chain peptide includes major histocompatibility complex class II restricted T-T cell interactions, Proc. Natl. Acad. Sci. USA 91 (1994) 5997-6001.

[21] J. Zhang, T-cell vaccination in multiple sclerosis: immunoregulatory mechanism and prospects for therapy, Crit. Rev. Immunol. 21 (2001) 41-55.

[22] A. Achiron, M. Mandel, T-cell vaccination in multiple sclerosis, Autoimmun. Rev. 3 (2004) 25-32.

[23] V. Kumar, E.E. Sercarz, The involvement of T cell receptor peptide-specific regulatory $\mathrm{CD}^{+} \mathrm{T}$ cells in recovery from antigen induced autoimmune disease, J. Exp. Med. 178 (1993) 909-916.

[24] Y.C. Zang, J. Hong, V.M. Rivera, J. Killian, J.Z. Zhang, Human anti-idiotypic T cells induced by TCR peptides corresponding to a common CDR-3 sequence motif in myelin basic protein-reactive T cells, Int. Immunol. 15 (2003) 1073-1080.

[25] R. Nayak, S. Mitra-Kaushik, M.S. Shaila, Perpetuation of immunological memory: a relay hypothesis, Immunology 102 (2001) 387-395.

[26] E. Harlow, D. Lane, Antibodies: A Laboratory Manual, Cold Spring Harbor, NY, 1988.

[27] S. Mitra-Kaushik, R. Nayak, M.S. Shaila, Identification of a cytotoxic T-Cell epitope on the recombinant nucleocapsid proteins of rinderpest and peste des petits ruminants viruses presented as assembled nucleocapsids, Virology 279 (2001) 210-220.

[28] K. Ohishi, K. Inui, K. Yamanouchi, T. Barrett, Cell mediated immune response in cattle vaccinated with a vaccinia virus recombinant expressing the nucleocapsid protein of Rinderpest virus, J. Gen. Virol. 80 (1999) 1627-1634.

[29] E.A. Elliott, J.R. Drake, S. Amigorena, J. Elsemore, P. Webster, I. Mellman, R.A. Flavell, The invariant chain is required for intracellular transport and function of major histocompatibility complex class II molecules, J. Exp. Med. 179 (1994) 681-694.

[30] L.S. Cauley, E.E. Miller, M. Yen, S.L. Swain, SuperantigenInduced CD4 T Cell Tolerance Mediated by Myeloid Cells and IFN- in document, J. Immunol. 165 (2000) 6056-6066.

[31] R.K. Pai, D. Askew, H.W. Boom, C.V. Harding, Regulation of class II MHC expression in APCs: Roles of type I, type III, and IV class II transactivator, J. Immunol. 169 (2002) 1326-1333.

[32] A. Truneh, F. Albert, P. Golstein, A.M. Schmitt-Verhulst, Early steps of lymphocyte activation bypassed by synergy between calcium ionophores and phorbol ester, Nature 313 (1985) 318-320.

[33] S. Mukherjee, P.K. Maiti, D. Nandi, Role of CD80, CD86 and CTLA4 on mouse CD4+ T lymphocytes in inhancing cell-cycle progression and survival after activation with PMA and Ionomycin, J. Leukoc. Biol. 72 (2002) 921-931. 
[34] Y. Takahama, H. Nakauchi, Phorbol ester and calcium ionophore can replace TCR signals that positive selection of CD4 T cells, J. Immunol. 157 (1996) 1508-1513.

[35] A. Noble, J.P. Truman, B. Vyas, M. Vukmanovic-Stejic, W.J. Hirst, D.M. Kemeny, The balance of protein kinase $\mathrm{C}$ and calcium signaling directs T cell subset development, J. Immunol. 164 (2000) 1807-1813.

[36] D. Hudrisier, J. Riond, H. Mazarguil, J.E. Gairin, E. Joy, Cutting Edge: CTLs rapidly capture membrane fragments from target cells in a TCR signaling-dependent Manner, J. Immunol. 166 (2001) 3645-3649.

[37] I. Hwang, J.F. Huang, H. Kishimoto, A. Brunmark, P.A. Peterson, M.R. Jackson, C.D. Surch, Z. Cai, J. Sprent, T cells can use either $\mathrm{T}$ cell receptor or $\mathrm{CD} 28$ receptors to absorb and internalize cell surface molecules derived from antigen presenting cells, J. Exp. Med. 191 (2000) 1137-1148.

[38] M.R. Walker, M.D. Mannie, Acquisition of functional MHC class II/peptide complexes by $\mathrm{T}$ cells during thymic development and CNS-directed pathogenesis, Cell. Immunol. 218 (2002) 13-25.

[39] J.Y. Tsang, J.G. Chai, R. Lechler, Antigen presentation by mouse CD4+ $\mathrm{T}$ cells involving acquired MHC class II:peptide complexes: another mechanism to limit clonal expansion?, Immunobiology 101 (2003) 2704-2710.

[40] R.N. German, L.R. Hendrix, MHC class II structure, occupancy and surface expression determined by post-endoplasmic reticulum, antigen binding, Nature 353 (1991) 134.

[41] S. Sadegh-Nasseri, R.N. Germain, A role for peptide in determining MHC class II structure, Nature 353 (1991) 167

[42] L.J. Stern, D.C. Wiley, The human class II MHC protein HLADR 1 assembles as empty $\alpha \beta$ heterodimer in the absence of antigenic peptide, Cell 68 (1992) 465.

[43] M.S. Anderson, J. Miller, Invariant Chain can function as a chaperone protein for class II major histocompatibility complex molecules, Proc. Natl. Acad. Sci. USA. 89 (1992) 2282.

[44] J. Lippincott-Schwartz, L. Yuan, C. Tipper, M. Amherdt, L. Orci, R.D. Klausner, Brefeldin A's effects on endosomes, lysosomes, and the TGN suggest a general mechanism for regulating organelle structure and membrane traffic, Cell 67 (1991) 601-616.

[45] Y.S. Pierre, T.A. Watts, MHC class II restricted presentation of naïve protein antigens by $\mathrm{B}$ cells is inhibitable by cyclohexamide and brefeldin-A, J. Immunol. 145 (1990) 812-818

[46] C. Alfonso, J.G. Han, G.S. Williams, L. Karlsson, The impact of H2-DM on humoral immune responses, J. Immunol. 167 (2001) 6348-6355.

[47] S.A. Huber, P. Skkinen, C. David, N.K. Newell, R.P. Tracy, Thelper cell phenotype regulates Atherosclerosis in mice under conditions of mild hypercholesterolemia, Circulation 103 (2001) 2610.

[48] S. Leibund Gut-Landmann, J.M. Woldberger, M. Krawczyk, L.A Otten, T. Suter, A. Fontana, H. Acha-Orbea, W. Reith, Specificity and expression of CIITA, the master regulator of MHC class II genes, Eur. J. Immunol. 34 (2004) 1513.

[49] J.A. Harton, J.P. Ting, Class II transactivator: mastering the art of major histocompatibility complex expression, Mol. Cell Biol. 20 (2000) 6185 .

[50] L.A. Otten, F. Tacchini-Cottier, M. Lohoff, F. Annunziato, L. Cosmi, L. Scarpellino, J. Louis, V. Steimle, W. Reith, H. AchaOrbea, Deregulated MHC class II transactivator expression leads to a strong Th2 bias in CD4+ T lymphocytes, J. Immunol. 170 (2003) 1150-1157.

[51] T. Gourley, S. Roys, N.W. Lukacs, S.L. Kunkel, R.A. Flavell, C.H. Chang, A novel role for the major histocompatibility complex class II transactivator CIITA in the repression of IL-4 production, Immunity 10 (1999) 377-386.

[52] S. Frosch, U. Bonifas, R. Rob, J. Schwing, H Yagita, Y. Guo, Y. Liu, A.B. Reske-kunz, Co-stimulatory signaling potential of murine MHC class II positive T cell clone cells, Immunology 89 (1996) 384-390

[53] D.B. Thomas, C.A. Smith, C.M. Graham, Viral Peptide Specific Induction of MHC Class II expression by murine T cell clones, $\mathrm{J}$. Immunol. 157 (1996) 2387-2394.

[54] C.H. Chang, S.C. Hang, C.C. Hughes, C.C. Janeway Jr., R.A. Flavell, CIITA activates the expression of MHC class II genes in mouse T cells, Int. Immunol. 7 (1995) 1515-1518.

[55] G.S. Williams, M. Malin, D. Vremec, C-H. Chang, R. Boyd, C. Benoist, D. Mathis, Mice lacking the transcription factor CIITAa second look, Int. Immunol. 10 (1998) 1957-1967.

[56] G. Tosi, N. Jabrane-Ferrat, B.M. Peterlin, Phosphorylation of CIITA directs its oligomerization, accumulation and increased activity on MHC class II promoters, EMBO J. 21 (2002) 5467.

[57] T-J. Sisk, K. Nickerson, R.P. Kwok, C.H. Chang, Phosphorylation of class II transactivator regulates its interaction ability and transactivation function, Int. Immunol. 15 (2003) 1195.

[58] M. Giroux, M. Schmidt, A. Descoteaux, INF- $\gamma$ induced MHC class II expression: transactivation of class II transactivator promotor IV by INF- $\gamma$ regulatory-1 is regulated by protein kinase C$\alpha$, J. Immunol. 171 (2003) 4187.

[59] W.S. Park, Y. Bae, D.H. Chung, Yoon-La Choi, B.K. Kim, Y.C. Sung, E.Y. Choi, S.H. Park, K.C. Jung, T cell expression of CIITA represses Th1 immunity, Int. Immunol. 16 (2004) 1355-1364.

[60] R. Hakamada-Taguchi, T. Kato, H. Ushijima, M. Murakami, T. Uede, H. Nariuchi, Expression and co-stimulatory function of B72 on murine $\mathrm{CD}^{+}{ }^{+} \mathrm{T}$ cells, Eur. J. Immunol. 28 (1998) 865-873.

[61] J.G. Chai, I. Bartok, D. Scott, J. Dyson, R. Lechler, T:T antigen presentation by activated murine $\mathrm{CD} 8^{+} \mathrm{T}$ cells induces anergy and apoptosis, J. Immunol. 160 (1998) 3655-3665.

[62] F. Bettens, E. Frei, K. Frutig, D. Mauri, W.J. Pichler, T. WyssCoray, Noncytotoxic human $\mathrm{CD}_{4} \mathrm{P}^{+} \mathrm{T}$-cell clones presenting and simultaneously responding to an antigen die of apoptosis, Cell Immunol. 161 (1995) 72-78.

[63] J.W. Chen, T.L. Murphy, M.C. Willingham, I. Pastan, J.T. August, Identification of two lysosomal membrane glycoproteins, J. Cell. Biol. 101 (1985) 85-95.

[64] M.D. Mannie, M.R. Walker, Feedback activation of T cell antigen presenting cells during interactions with $\mathrm{T}$ cell responses, J. Leukoc. Biol. 70 (2001) 252-260.

[65] K. Stenseth, J. Thyberg, Monensin and chloroquine inhibit transfer to lysosomes of endocytosed macromolecules in cultured mouse peritoneal macrophages, Eur. J. Cell Biol. 49 (1989) 326-333.

[66] A. Lanzavecchia, E. Roosnek, T. Gregory, P. Berman, S. Abrignani, T cells can present antigens such as HIV gp120 targeted to their own surface molecules, Nature 334 (1988) 530-532.

[67] M. Saifuddin, G.T. Spear, C. Chang, K.A. Roebuck, Expression of MHC class II in T cells is associated with increased HIV-1 expression, Clin. Exp. Immunol. 121 (2000) 324-331. 